\title{
Gender and Persistence in Negotiation: A Dyadic Perspective
}

\section{Citation}

Bowles, Hannah Riley, and Flynn, Francis. "Gender and Persistence in Negotiation: A Dyadic Perspective.(Report)." Academy of Management Journal 53, no. 4 (2010): 769-787.

\section{Permanent link}

http://nrs.harvard.edu/urn-3:HUL.InstRepos:37865891

\section{Terms of Use}

This article was downloaded from Harvard University's DASH repository, and is made available under the terms and conditions applicable to Other Posted Material, as set forth at http:// nrs.harvard.edu/urn-3:HUL.InstRepos:dash.current.terms-of-use\#LAA

\section{Share Your Story}

The Harvard community has made this article openly available.

Please share how this access benefits you. Submit a story.

\section{Accessibility}




\title{
GENDER AND PERSISTENCE IN NEGOTIATION: A DYADIC PERSPECTIVE
}

\author{
HANNAH RILEY BOWLES \\ Harvard University \\ FRANCIS FLYNN \\ Stanford University
}

\begin{abstract}
We studied interactive effects of gender in negotiation dyads, theorizing that the degree and manner of a negotiator's persistence are functions of the gender composition of the dyad. Our findings challenge sex-stereotypic perspectives, showing that women persist more with male naysayers than with female naysayers but do so in a stereotypically low-status (more indirect than direct) manner. Women's adaptation of their persistence to naysayer gender appeared functional because increased persistence with male naysayers helped close a gender gap in performance, and female negotiators with high performance adjusted their manner of persistence more than those with low performance.
\end{abstract}

Negotiation is a fundamental form of coordination in organizations that affects the process of work, the resolution of conflict, and the advancement of careers (Barley, 1991; De Dreu \& Gelfand, 2007; Pfeffer, 1981). The study of gender in negotiation is important to the understanding of organizational processes because gender is an essential and pervasive source of diversity at work (Bielby \& Baron, 1986; Ely \& Meyerson, 2000; Goldin, 1990; Heilman, 1983) and because negotiation is one of the micromechanisms through which gender inequalities in organizations are both constructed and broken down (Bowles \& McGinn, 2008).

The focus of the current article is how gender affects persistence in negotiation-the willingness to continue seeking compromise from a naysaying counterpart. We examined the degree of persistence, in terms of the propensity for negotiators to stand their ground rather than yield. We also examined the manner of persistence, in terms of the extent to which negotiators rely on direct verbal communication or more indirect nonverbal cues to express dissatisfaction with current offers. We focused on these particular elements of the manner of persistence because they are linked theoretically to gender and other forms of social status (Carli, 1990; Falbo \& Peplau, 1980; Howard, Blumstein, \& Schwartz, 1986; Johnson, 1976).

Persistence-in this sense of task perseverancehas long been associated with both individual negotiation performance (Siegel \& Fouraker, 1960) and the achievement of joint gains (Ben-Yoav \&
Pruitt, 1984). Yet it has received scant attention in the quest to understand gender effects on negotiation. Perhaps this is because sex stereotypes offer such an intuitive answer to the question of how gender will affect negotiators' willingness to accept "no" for a response. Sex stereotypes clearly suggest that persisting in the face of another's intransigence is the "masculine" as opposed to the "feminine" response. Prominent measures of gender identity associate masculinity with attributes such as "willing to take a stand" and "defend my own beliefs" and femininity with traits such as "understanding" and "sympathetic" (Bem, 1981; Spence \& Helmreich, 1978). Therefore, if men and women followed the sex stereotypes, men would be more likely to stand their ground, whereas women would be more inclined to accommodate or compromise.

We argue, however, that actual persistence behavior in negotiation is not a simple reflection of sex stereotypes. Analyzing the meaning of gender in negotiation contexts, we propose that gender effects on negotiation persistence are better predicted by the gender pairing in a dyad than by the gender of an individual negotiator. We theorize that the effects of sex stereotypes in negotiation are a product of expectations for the self and other in interaction. Drawing on this interactive interpretation of the effects of sex stereotypes, we propose that women may adjust both the degree and manner of their persistence, depending on a naysayer's gender (i.e., the gender of a negotiating counterpart who is refusing to make asked-for concessions). We argue that women persist to a greater degree with male than female naysayers 
but in a characteristically low-status manner (i.e., more indirect than direct) that implicitly appeals to men's higher status in the gender hierarchy.

The theoretical contributions of this work are threefold. First, we offer a theoretically grounded perspective on an important yet neglected phenomenon in negotiation research. In doing so, we begin to fill an important gap in the study of gender in negotiation, which has focused primarily on how gender affects precursors to negotiation (e.g., propensity to negotiate, aspirations) and negotiation outcomes (e.g., individual and joint performance) (Kray \& Thompson, 2005). We illuminate effects of gender on the negotiation process itself that have remained thus far only dimly lit (cf. Walters, Stuhlmacher, \& Meyer, 1998).

The second contribution of this work is to advance negotiation theory with regard to the analysis of gender effects at the dyadic level. As explained in greater depth below, most research on gender in negotiation represents the perspective of either a focal negotiator or that person's negotiating partner, rather than analyzing how these two perspectives interact. How the gender composition of a dyad affects negotiation is a subject in need of more rigorous theoretical development (Kray \& Thompson, 2005). Taking inspiration from theories of gender in context (Deaux \& LaFrance, 1998; Deaux \& Major, 1987) and of sex stereotypes in negotiation (Kray \& Thompson, 2005), we propose a theoretical frame for deepening the analysis of gender effects at the dyadic level.

The third contribution is a complication of the "damned if you do, doomed if you don't" (Catalyst, 2007) message conveyed by much of the contemporary research on gender in negotiation. Studies have shown that when men and women fulfill traditional sex stereotypes in negotiation, men claim more value than women (Babcock \& Laschever, 2003; Kray, Thompson, \& Galinsky, 2001). However, when men and women use the same assertive negotiating script, women suffer a higher social cost for their behavior than do men (Bowles, Babcock, \& Lai, 2007). Does this mean that women as negotiators are trapped? We argue that closer examination of negotiation processes shows that women do engage in assertive negotiating behavior-such as persistence against an intransigent counterpartbut adapt their behavior to the social context. Indeed, we find "higher-performing" female negotiators may be more likely to adjust the manner of their persistence behavior to suit their counterparts' gender.

\section{THE DYADIC PERSPECTIVE}

Negotiation researchers have tended to hypothesize as to how either the gender of a focal negotiator or the gender of her/his counterpart influences negotiations. With regard to the focal negotiator, the pursuit of consistent sex-stereotypic differences between male and female negotiators has produced a mixed bag of results. There is meta-analytic evidence that men (as compared to women) behave more competitively and claim more economic value in negotiation (Stuhlmacher \& Walters, 1999; Walters et al., 1998). However, these main effects do not hold in all negotiation contexts, in large part because women's behavior tends to vary across situations (Rubin \& Brown, 1975). For instance, sexstereotypic gender differences in competitiveness are strongest when negotiators are interacting face to face, because women behave more competitively in text-based and anonymous interactions (Stuhlmacher, Citera, \& Willis, 2007; Walters et al., 1998). Sex-stereotypic negotiation outcomes are more likely when negotiators are representing themselves as opposed to others, because women negotiate higher payoffs advocating for others than for themselves (Bowles, Babcock, \& McGinn, 2005).

Other research has examined the attributions that focal negotiators make on the basis of the gender of their negotiating partner (see Kray and Thompson [2005] for a review). These studies have shown a clear pattern of sex-stereotypic attributions toward male and female negotiators. Negotiators expect male partners to be more self-interested and competitive than female partners and expect female partners to be more other-concerned and cooperative than male partners (Burgoon, Dillard, \& Ooran, 1983; King, Wesley, Miles, \& Kniska, 1991; Kray et al., 2001; Matheson, 1991; Orbell, Dawes, \& Schwartz-Shea, 1994). For instance, Kray et al. (2001) found that MBA students perceived men to have the advantage over women in negotiation. The three most common reasons offered were "men do not want to lose to women," "men are more competitive and aggressive," and "men are less willing to compromise/women will accommodate" (Kray et al., 2001: 958).

Little attention has been paid to how these two perspectives might interact. Kray and Thompson (2005) suggested the interactive effects of gender at the dyadic level could contribute to a dynamic of behavioral confirmation (Snyder \& Swann, 1978) or self-fulfilling prophecy (Rosenthal, 1994; Word, Zanna, \& Cooper, 1974) in which negotiators act out their partners' stereotypic expectations. However, they pointed out that there is little direct evidence of behavioral confirmation in negotiation 
research. Moreover, these theories do not explain why, in spite of remarkably consistent sex-stereotypic expectations, the effects of gender on a focal negotiator's performance vary across situations. In other words, negotiators-particularly female negotiators-do not always fulfill the stereotype (Rubin \& Brown, 1975).

Kray and Thompson (2005) also suggested that the gender composition of a negotiating dyad moderates the salience of sex stereotypes (viz., they are more salient in mixed-gender than same-gender dyads). This proposition would be consistent with the effects these authors observed in their stereotype activation research. For example, Kray et al. (2001) showed that the implicit activation of sex stereotypes favoring masculine characteristics in negotiation performance increased the male advantage in negotiation payoffs-but only in mixed-gender pairs. They argued that their manipulations produced more stereotype-consistent effects in mixed-gender than in same-gender pairs because the mixed-gender context made sex stereotypes more salient.

We support the view that the gender composition of a dyad is an important-if not fundamentalsituational variable, but we argue that its significance may relate to the meaning, as well as the salience, of gender in context. For instance, another possible interpretation of the Kray et al. (2001) finding just described is that the information about a masculine performance advantage carried different implications depending on whether negotiators were paired with same- or opposite-gender partners. The information has identical implications for both men and women paired with a same-gender partner: "I have as good of a shot as my partner of doing well in this negotiation." However, in mixed-gender pairs, the information about a masculine advantage conveys distinct messages to male and female negotiators.

To develop the theoretical proposition that the gender composition of a dyad alters the meaning of gender in the negotiation context, we take inspiration from theories of gender as socially constructed in the context of interpersonal interaction (e.g., Deaux \& Major, 1987). We argue that gender effects on persistence in negotiation reflect the strategic implications of the content of sex stereotypes as well as gender-linked status (a)symmetries within a pair-both of which hinge upon the gender of the focal negotiator and the gender of the negotiating partner.

\section{GENDER AND PERSISTENCE IN NEGOTIATION}

Theories of gender as socially constructed in the context of interaction take into account what Deaux and Major (1987) called the "distal causes" for gender differences in social behavior. These factors include the tendency in society for men to hold positions of higher authority than women and to control greater economic resources (Ridgeway \& Bourg, 2004) and the socialization of men and women into gender roles that reflect their relative social and economic statuses (Conway, Pizzamiglio, \& Mount, 1996; Eagly \& Steffen, 1984). Distal influences-status expectations (Ridgeway, 1997), gender roles (Eagly, 1987), and so forthshape people's understanding of what it means to be a man or a woman and how men and women rank in the social hierarchy (Ridgeway, 1997; West \& Zimmerman, 1987).

Theories of gender in context also emphasize the importance of what Deaux and Major (1987) called the "proximal causes" of gender effects, which are situational factors that activate gendered self-concepts and behavioral expectations (Ridgeway, 1997; West \& Zimmerman, 1987). As Deaux and Major explained, "People in interaction are simultaneously perceivers of others, targets of others' perceptions, and perceivers of themselves" (1987: 370). The context of interaction cues "gender belief systems" in relation to the self and the other. Gender belief systems are sets of beliefs about how men and women do and should behave (e.g., sex stereotypes) in a particular context (Deaux \& Kite, 1987). They inform both the enactment and interpretation of social behavior within the situation.

The distal influences of men's and women's respective roles and places in society evolve and vary across cultural contexts (Diekman \& Eagly, 2000; Glick et al., 2000). Nonetheless, gender belief systems remain an organizing force even in the most progressive societies (Charles \& Bradley, 2009; Ridgeway, 2006), and status-linked behavioral constraints continue to place limits on even the most powerful women in society (Eagly \& Carli, 2007). The proximal causes of gender effects, too, are fluid, sensitive to factors such as the distribution of men and women in an organization (Ely, 1995), the gendered character of a task (Heilman \& Okimoto, 2007), and the degree of ambiguity with regard to task expertise (Wood \& Karten, 1986). However, in the context of negotiation, associations between negotiation and masculine dominance are remarkably robust (Kray \& Thompson, 2005).

\section{Gender and the Degree of Negotiation Persistence}

As described above, the predominate beliefs about men and women in negotiation are that men are competitive and women cooperative and, as a result, men are more effective negotiators than 
women. Although men and women both hold these beliefs (e.g., Kray et al., 2001), we argue that they have different strategic implications for male and female negotiators, particularly with regard to their propensity to persist with an intransigent counterpart.

We motivate this proposition by drawing on Kelley and Stahelski's (1970) classic work on cooperative and competitive types, which showed that competitive (as compared to cooperative) types tend to hold more uniform expectations about the behavior of others in the context of mixed-motives interactions (i.e., situations with incentives both to cooperate and to compete, such as negotiation). According to Kelly and Stahelski, competitive types learn over time to anticipate competitive behavior from others because their own behavior tends to elicit competitive behavior from both competitive and cooperative types. Cooperative types, in contrast, are more likely to believe that there are some with whom they can cooperate and others with whom they must compete, because that is their experience. Kelley and Stahelski's types refer to personality differences. However, we propose that the same logic should apply as well to stereotypic types-regardless of whether the stereotype is attributed or self-fulfilled.

In a mixed-motive context, those whom others type as competitive (regardless of actual type) are more likely to elicit competition because the others believe that they need to compete with them. As a result, negotiators who are thus "competitively typed" by others are likely to develop more uniform expectations for others' behavior. Those negotiators who self-stereotype as competitive are also less likely to adapt their negotiation behavior, or "play," to the competitive or cooperative type of their counterparts, because their dominant choice is to compete, regardless of the others' type. In contrast, those who are cooperatively typed by others are likely to elicit a mix of cooperative and competitive play, depending on counterpart type. Congruently, those who self-stereotype as cooperative should engage in a mix of cooperative and competitive play-cooperating with cooperative types and shifting to competing, or at least behaving less cooperatively (e.g., persisting more), with competitive types to avoid exploitation.

Although this logic has not been tested in relation to sex stereotypes in negotiation, there is evidence that women act in more stereotypically feminine, cooperative ways with other (cooperatively stereotyped) women than with (competitively stereotyped) men. It appears women learn-consciously or unconsciously-from an early age to "play tougher" with boys.

Studies of child development show that by mid- childhood, girls have adapted their interaction styles (more than boys have) to the gender of their play partner. Same-gender play among girls tends to be affiliative and collaborative, whereas samegender play among boys tends to be more controlling and competitive (Cherry Wilkinson, Lindow, \& Chiang, 1985; Leaper, 1991; Maccoby, 1998; Sheldon, 1990, 1992; Strough \& Berg, 2000). These gender differences become less pronounced in mixedgender play because girls tend to change their interaction style to be more assertive with boys than with girls (Cherry Wilkinson et al., 1985; Goodwin \& Goodwin, 1987; Hall, 1984; Sgan \& Pickert, 1980; Strough \& Berg, 2000), whereas boys' style varies relatively little (Leaper, 1991; Leaper \& Holliday, 1995; McCloskey \& Coleman, 1992; Miller, Danaher, \& Forbes, 1986; Strough \& Berg, 2000). Child psychologists have argued that girls adapt their play styles to the gender of their play partners because they find it necessary to use more assertive behavior to influence boys (Leaper, 1991; Maccoby, 1998).

Patterns of childhood interaction are not carried over intact into adulthood, but there are parallels (Maccoby, 1998). Similarly to the child development studies, studies of adult social interaction have shown that differences in the social behavior of adult men and women tend to be more pronounced in same-gender than in mixed-gender interactions, with women together being more cooperative and affiliative (i.e., "communal") than men together (Calhoun \& Smith, 1999; Kimmel, Pruitt, Magenau, Konar-Goldband, \& Carnevale, 1980; Moskowitz, Suh, \& Desaulniers, 1994; Wood, 1987). To the extent that gender differences in social behavior tend to be less pronounced in mixed-gender than in same-gender interactions, it is generally because women behave less communally (e.g., agreeably) with men than women (Deaux \& LaFrance, 1998; Grant \& Sermat, 1969; Hall, 1984; Moskowitz et al., 1994; Piliavin \& Martin, 1978).

In sum, the competitive (masculine) and cooperative (feminine) sex stereotypes in negotiation carry distinct strategic implications depending on whether one is paired with a competitively (masculine) or cooperatively (feminine) typed negotiating partner. As compared with competitively stereotyped (male) negotiators, cooperatively stereotyped (female) negotiators have greater motivation to adapt their behavior in view of their negotiating partner's stereotype and to behave more competitively with competitive types to avoid exploitation. Applying this logic to persistence in negotiation, we argue that women adjust the degree of their persistence behavior (i.e., persist more or less) depending on their counterpart's gender and 
that they become more persistent with male than female naysayers.

However, if this simple prediction is supported, an alternative explanation for the effect could be that male partners actually did negotiate more competitively with female negotiators than did female partners and, thereby, elicited differential treatment in the form of greater persistence. To rule out this alternative possibility, we examined the proposition that female negotiators persist more with male than female naysayers even when the competitiveness of the naysayer's negotiating behavior is controlled for.

Hypothesis 1. Female negotiators persist more with male than female naysayers, with the competitiveness of the naysayers' negotiating behavior controlled for.

Thus far, we have examined how the gender composition of a dyad alters the strategic implications of gender belief systems in negotiation. We have theorized that the strategic implications of sex stereotypes in negotiation influence the degree of women's persistence (i.e., higher with male than female naysayers). In the following section, we explain why the gender composition of a dyad also influences the manner of women's persistence in negotiation.

\section{Gender and the Manner of Negotiation Persistence}

Lower-status actors, such as women as compared to men, face greater constraints on what constitutes appropriate influence behavior, both in general (Brown \& Levinson, 1987; Keltner, Young, Heerey, Oemig, \& Monarch, 1998; Meeker \& WeitzelO’Neill, 1977; Ridgeway, 1982) and in negotiation situations specifically (Bowles et al., 2007). Particularly in interaction with higher-status others, acting out of role-defying the behavioral prescriptions for one's status-is more problematic for those of lower status because it implicitly threatens the social hierarchy (Carli, LaFleur, \& Loeber, 1995; Jackman, 1994; Rudman \& Glick, 2001).

When shifting between interacting with women and men, women move from an equal- to a lowerstatus social position in the gender status hierarchy, and research has suggested that it behooves women to adopt an influence style congruent with their relative place in the social interaction. For example, Carli (1990) found that women varied their style of speech more than men depending on the gender of their interaction partner and that women used a more stereotypically low-status (i.e., more tentative) speech style with men than with women. Women were significantly more influential with men (but not women) when they made their case in a stereotypically low-status style, but the effectiveness of men's style of speech was not contingent on the gender of their interaction partner. Because of this shift in social status that women incur in mixed- versus same-gender dyads, we propose that women alter the manner in which they persist in negotiation with a naysayer depending on the naysayer's gender and use a lower-status influence style with male naysayers than with female ones.

What constitutes a lower-status influence style? One measure of social influence that has been linked to gender and other status hierarchies is the degree of reliance on indirect as opposed to direct forms of influence (Carli, 1990; Cowan, Drinkard, \& MacGavin, 1984; Falbo \& Peplau, 1980; Howard et al., 1986; Johnson, 1976). For instance, one can communicate displeasure in a direct way through a verbal demand (e.g., "I want you to do something different"). Alternatively, one could communicate the same type of displeasure in an indirect way using nonverbal or emotional expressions (e.g., a sad face). Research has shown that women in heterosexual couples (and lower-status partners in homosexual couples) use fewer direct demands and rely more on these indirect tactics, such as acting emotional, to get their way (Falbo \& Peplau, 1980; Howard et al., 1986).

Lower-status actors tend to develop more indirect styles of influence, in part because they have less social control and fewer resources they can use to get their way (Johnson, 1976), but also because using directly assertive influence strategies may be perceived as a status violation, especially in interactions with higher-status targets (Carli, 1990; Meeker \& Weitzel-O’Neill, 1977; Ridgeway, 1982). Use of an indirect style of influence by a lowerstatus actor toward a higher-status target implicitly cues recognition of the status hierarchy and should, as a result, make the actor's requests or assertions more palatable. Applying this logic to persistence in negotiation, we predict that women use more indirect than direct forms of influence (e.g., nonverbal expression versus verbal demands) when persisting with male as compared to female naysayers.

Hypothesis 2. Female negotiators use a more indirect than direct style of influence when persisting with male naysayers than they use with female naysayers.

\section{Persistence and Performance in Negotiation}

Persistence is not necessarily predictive of task performance (McFarlin, Baumeister, \& Blascovich, 
1984), but it has been associated with enhanced performance in a wide range of individual and interactive task domains (Bandura, 1982; Dweck \& Gilliard, 1975; Locke \& Latham, 2002), including activities that are closely related to negotiation, such as sales (Seligman \& Schulman, 1986) and fundraising (Grant, Campbell, Chen, Cottone, Lapedis, \& Lee, 2007). Generally perceived as a fundamental driver of negotiation performance (Ury, 1993), persistence can improve individual payoffs and even facilitate joint gains to the extent that personal objectives do not crowd out the search for mutually beneficial solutions (De Dreu, Weingart, \& Kwon, 2000; Pruitt, 1998). Therefore, we posit that greater persistence with an intransigent counterpart (e.g., taking more time to reach an agreement, asking for additional concessions) leads to higher individual payoffs for both male and female negotiators.

Hypothesis 3. Negotiators' degree of persistence against a naysayer is positively correlated with their individual economic payoffs from a negotiation.

We argued above that it is functional for women to alter their influence style depending on the gender of their negotiating counterpart because they are more influential when they communicate in a way that is congruent with their relative social status (e.g., Carli, 1990). On the basis of this argument, we predict that high-performing female negotiators (i.e., those with higher individual economic payoffs) adjust the manner in which they persist (i.e., reliance on indirect vs. direct influence) more than low-performing female negotiators, depending on the naysayer's gender.

Hypothesis 4. The predicted effect of naysayer gender on the manner of female buyers' persistence (i.e., using more indirect than direct influence behaviors with male than with female naysayers [Hypothesis 2]) is significantly stronger for high-performing than for low-performing female negotiators.

\section{OVERVIEW OF STUDIES}

We have proposed that the gender composition of a negotiation dyad-specifically, the interaction between focal negotiator gender and counterpart gender-is more predictive of persistence behavior than the gender of the focal negotiator because the meaning of gender in negotiation shifts with the genders of the two parties. Specifically, we have hypothesized that women become more persistent with male than with female partners, using a more stereotypically low-status style of influence.

We tested our hypotheses in two negotiation studies in which we gave men and women the same motivation to persist and controlled the concession-making ability of their nay-saying counterparts. In Study 1, participants negotiated with male or female confederates who followed a narrow script of resistance. We tested whether male and female negotiators described their behavior in global sex-stereotypic terms (i.e., men claiming to be more persistent than women) or whether, as predicted, gender effects reflected the gender composition of the dyads. In Study 2, one side (the "persister") was motivated to seek concessions that the other side (the "naysayer") could not provide. We collected observation-based measures of the degree and manner of persistence and results of negotiation performance.

\section{STUDY 1}

Study 1 had a $2 \times 2$ (persister gender by naysayer gender) between-subjects experimental design involving a single-issue price negotiation. For all studies, we used self-identification as male or female as our measure of gender.

\section{Methods}

Participants. Participants were 77 university students and staff (95 percent students; 29 men, 48 women) recruited through a research laboratory at a West Coast university. The average age was 20 years. The sample was 79 percent from the United States (37\% Asian; 28\% white; 18\% Hispanic; 9\% black; $8 \%$ other). Participants signed up expecting to receive five dollars for participating and to have the opportunity to earn more money if they performed well on the exercise.

Materials. The negotiation exercise was an adapted version of an existing simulation, a singleissue negotiation over the sale price of a four-bedroom house (Blount, 1997). We selected this case because of its simplicity and its "androgynous" context (Bem, 1981). Although competitive price negotiations are generally masculine-stereotyped, residential house sales are widely recognized as a feminized work domain (e.g., Wharton, 2002).

Each participant received confidential instructions about their aspirations and walk-away price for the negotiation plus background information on the house (e.g., amenities, comparable sales). Participants had ten minutes to prepare for the negotiation. Half played the role of buyer and were paired with a confederate seller, and half played 
the role of seller and were paired with a confederate buyer. Regardless of their role as buyer or seller, participants were assigned the same price aspiration $(\$ 475,000)$, which was $\$ 25,000$ dollars away from their respective walk-away values. Confidential instructions indicated that participants could earn an additional $\$ 1$ for every $\$ 5,000$ they negotiated on the sales price above (for sellers) or below (for buyers) their walk-away price.

Procedures. A female research assistant ran the study, randomly assigning participants to negotiate with one of four confederates (two men, two women) and counterbalancing participants' roles as buyer or seller. The research assistant and confederates were blind to the hypotheses.

We recruited two male and two female confederates to avoid confounding gender and confederate effects. The confederates were undergraduate students from the same university community as the participants. To minimize heterogeneity among the confederates, we recruited white, native-Englishspeaking students of average height and build.

We trained the confederates to wait for the participants to initiate the negotiation and then to make the first offer. Confederate sellers made offers $\$ 25,000$ higher than the buyers' maximum price, and confederate buyers made offers $\$ 25,000$ lower than the sellers' minimum price. The confederates justified their initial offers on the basis of comparable sales information available in the background information. Because these offers were outside the range of possible agreement, the participants had to respond with a counteroffer if they wanted an agreement.

During the negotiation, the confederates limited their speech to seven alternative statements that communicated a lack of willingness to make concessions (e.g., "I am giving you what I think is a fair offer," "I think that the market value of the house is [offer]"). We also coached the confederates to use the same nonverbal scripts (e.g., exhibit calm demeanor, use even tone of voice and casual eye contact, avoid crossing arms or legs). We practiced with the confederates until they were comfortable with both the verbal and nonverbal scripts.

The participants' negotiating instructions and the confederates' scripts made it impossible to reach agreement. Therefore, each negotiation concluded when the participant gave up.

Measures. Following the negotiation, participants reported their negotiation outcome. By design, all of the participants reported that they had not reached agreement.

Our measure of self-reported persistence included three items rated on a seven-point agreedisagree scale: (1) "I stood my ground," (2) "I compromised easily" (reverse-scored), and (3) "I was as accommodating as possible" (reverse-scored) ( $\alpha=$ .72). Item 1 is characteristic of masculine assertiveness, whereas items 2 and 3 reflect the feminine stereotype, as discussed above (e.g., see Bem, 1981; Spence \& Helmreich, 1978). Higher scores indicated a more stereotypically masculine (less feminine) response to a nay-saying counterpart.

Finally, to test for suspicion about the confederate's intransigence, we asked participants what percentage of participants they thought reached agreement ( $1=$ "none," $2=$ " $1-10 \%, " 3=$ " $11-20 \%$," $4=$ "21-30\%" . . 11 = "91-100\%”). Participants guessed the percentage was low but significantly greater than 0 (mean $=3.50$, s.d. $=2.06 ; t[74]=$ $10.52, p<.001, d=2.45$ ), and there was no significant variation in this estimation by condition $\left(F_{\mathrm{s}}<\right.$ $0.66)$.

After submitting their postnegotiation surveys, participants completed an exit survey including demographic items and questions about how well they knew their negotiating counterpart (the confederate) prior to the study. We were concerned about familiarity because pretesting indicated that it undermined the plausibility of the script.

Before leaving, participants were debriefed about the deception. We paid all subjects $\$ 10$, the amount they would have received if they had negotiated an agreement at their target price.

\section{Results}

We excluded three cases from the analysis because data were incomplete and excluded two cases in which the participants indicated they knew the confederates well (i.e., knew them prior to the study and were "highly likely" to interact again). The final sample included 29 men and 43 women.

Analyses of variance showed no effects of buyer/ seller role $\left(F_{\mathrm{S}}<1.73, p\right.$ 's $\left.>.19\right)$ and no confederatespecific effects on persistence $(F \mathrm{~s}<0.46)$. Because the sample was racially diverse and we used white confederates, we also tested for main or interactive effects of participant race and found none $\left(F_{\mathrm{S}}<0.37\right)$.

As predicted, ANOVA revealed a significant interaction effect of persister gender by naysayer gender on persistence $(F[1,68]=4.63, p=.04$, $\left.\eta^{2}=0.06\right)$. There were no significant main effects for participant or confederate gender $\left(F_{\mathrm{S}}<1.10\right.$, $p$ 's $>$.29).

As depicted in Figure 1, the pattern of means supported Hypothesis 1, which states that female negotiators persist more with a male naysayer than with a female naysayer. Even though the male and female confederates (the naysayers) followed the same negotiating script, female participants reported persisting more with the men $(t[41]=2.16, p<.04, d=0.67$; 
FIGURE 1

Study 1: Mean Persistence by Persister Gender and Naysayer Gender ${ }^{a}$

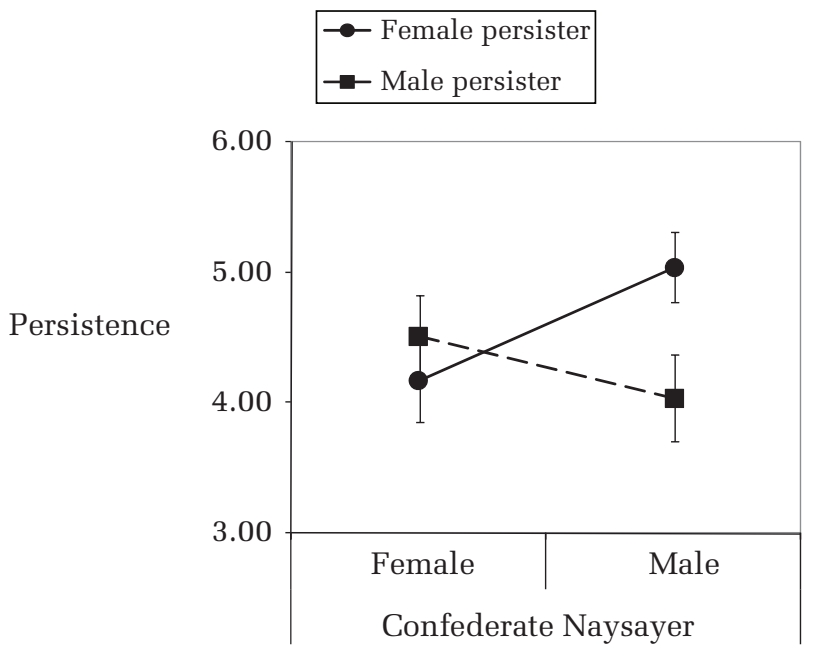

a The dashed line indicates no significant difference in men's persistence by confederate gender. The solid line indicates significant difference in women's persistence toward male versus female confederates at the level of $p<.05$. Error bars indicate \pm 1 s.e.

female confederate mean $=4.17$, s.d. $=1.37$; male confederate mean $=5.04$, s.d. $=1.30$ ). Female participants actually reported persisting more with male confederates than did male participants $(t[35]=2.30$, $p=.03, d=0.78$ ), but not with female confederates $(t[33]=0.77, p=.45, d=0.27)$. For male participants, confederate gender had no significant effect on reported persistence $(t[27]=1.01, p=.32, d=0.38$; female confederate mean $=4.51$, s.d. $=1.23$; male confederate mean $=4.05$, s.d. $=1.25$ ).

\section{Discussion}

Contrary to the sex stereotype, we found no main effect gender difference in reported persistence. As predicted, naysayer gender moderated gender differences in reported persistence, and women reported persisting more strongly with male than with female naysayers. In keeping with the proposition that negotiators draw sex-stereotypic inferences from the gender of their negotiating counterparts, these effects were observed in spite of the fact that we restricted the nay-saying confederates to a narrow script of resistance. Therefore, differential treatment of male and female negotiators could not explain the results.

One limitation of this study is that we relied on self-reported measures of persistence. However, self-report measures are arguably even more prone than observational measures to sex-stereotypic fulfillment, and our findings still defied the sex-stereotypic expectations. We sought to replicate and expand upon the results of Study 1 in Study 2, in which we collected a richer array of observationbased measures to test our predictions with regard to both the degree and manner of persistence in negotiation. We also used a multi-issue dyadic negotiation, which enabled tests of effects of persistence on individual negotiation performance.

\section{STUDY 2}

Study 2 had a $2 \times 2$ (persister [buyer] gender by naysayer [seller] gender) between-subjects experimental design. We collected observation-based measures of the degree and manner of negotiation persistence and data on negotiation performance.

\section{Methods}

Participants. Participants were 114 students (56 men, 58 women) from multiple universities within a single metropolitan area in the Northeast. The mean age was 21.05 years. Participants were 82 percent from the United States (63\% white; $16 \%$ Asian; $11 \%$ black; $7 \%$ Hispanic; $4 \%$ other). Participants received $\$ 10$ for showing up for the study and had the opportunity to earn more money with good performance. The average payment was $\$ 21$.

Materials. The exercise used was a two-party, multi-issue, scored negotiation over the acquisition of a family-owned food export business (Bontempo, 1994). Each party received four pages of confidential instructions, including explanations of each of the issues to be negotiated, a scoring sheet for calculating the value of various agreements for his or her role only, and general negotiating instructions (e.g., "You will receive $\$ 2.00$ for every 100 points you gain in the negotiation. . . . You must reach agreement on all four issues. ... You must never show the other party your payoff table"). The Appendix presents the information contained in the scoring sheet.

As shown in the Appendix, the parties had four issues to resolve (i.e., payment terms, noncompete period, retention of family employees, and legal liability), and there were 11 options for resolving each issue. Participants could negotiate the issues separately or collectively (e.g., making trade-offs between issues) in whatever order they chose. For the first three issues listed in the Appendix, the parties had opposing interests but differing valuations of the issues' relative importance (as indicated by the points per option/issue). On the legal liability issue, we adjusted the scoring so that the buyers had a strong motivation to persist for concessions (i.e., offloading the legal liability was their highest-value issue), and the sellers (naysayers) were constrained from making 
concessions (i.e., sellers could not make a deal if they accepted any legal liability).

Although the buyers' persistence on the legal liability issue could not pay off in terms of seller concessions on that specific issue, we anticipated that persistence on it would help the buyers gain concessions on other issues (e.g., "I'll relieve you of any liability, but I need you to do more for me on something else"). We therefore anticipated that higher persistence on the legal liability issue would lead to higher overall performance for the buyers.

Procedures. A total of six research assistants (two men, four women) were involved at various times in running the study sessions. All were blind to the hypotheses.

At the start of each session, two research assistants randomly assigned participants to buyerseller negotiating pairs and distributed confidential instructions to prepare for the negotiation. After reviewing their instructions, the buyer-seller pairs were ushered into separate breakout rooms. Each room was equipped with a table and two chairs and a digital video camera visible to the participants. We used a wide-angle lens to capture the two participants in interaction.

Before the negotiation, the research assistants confirmed that none of the participants were negotiating with someone they knew. Participants were given 20 minutes to negotiate. After negotiating, they completed an exit survey that included demographic items.

Video coding. Two female undergraduate research assistants who were blind to the hypotheses helped with the development of the coding scheme and coded all of the videotaped sessions. We used a pretest sample of 12 negotiations to develop the scheme.

We (the authors) generated the first draft of the coding scheme through an iterative process of observation and conversation about the dynamics within the negotiating pairs and a review of measures of bargaining behavior (e.g., see Diekmann, Tenbrunsel, \& Galinsky, 2003; Pruitt, 1981; Walton \& McKersie, 1965). Prior to the test run for each subsequent draft of the coding scheme, we reviewed the items with the coders, discussing examples of the types of behaviors the codes were intended to represent. After each test run, we compared the coders' ratings to our own expectations for how various negotiating behaviors would be perceived. We debriefed each test run with the coders and revised the coding scheme to incorporate their feedback and observations and to meet our theoretical interests.

The coding training process also involved some education in basic negotiation concepts. For instance, the research assistants negotiated the case once together to gain familiarity with the scoring system and process. We debriefed this experience with them, highlighting important elements of the case structure (e.g., motivation for persistence on the liability issue) and explaining basic negotiation concepts relevant to the coding.

For the final coding, it took the research assistants 45 minutes to an hour to process each video because they had to review each tape multiple times (pausing several times along the way). On their first pass through the video, the coders focused primarily on the buyers' behavior during the segments of the negotiation in which the parties were discussing legal liability, because that was the issue in which we created the motivation for buyers to persist. After coding the buyers' persistence behavior, the coders took a second pass through the video focusing on the sellers' (naysayers') behavior in the overall negotiation.

We asked the coders to focus on the sellers' (the naysayers') overall behavior because measures of the sellers' resistance on the liability issue were not particularly meaningful, given that they had only one possible way of resolving that issue (i.e., accepting none of the liability). The sellers' negotiation behavior was constrained on the liability issue, yet they could respond freely on other issues. Because the sellers' general behavior during the negotiation might influence the buyers' persistence on the liability issue, we asked the coders to assess how competitively the sellers (the naysayers) behaved overall in the negotiation.

Both research assistants independently coded the first half of the tapes. Using these joint ratings, we report the single-measure intraclass correlation coefficient (ICC) for each measure below (ICC mean $=.87$ ). Reassured by a high degree of intercoder reliability, we had the rest of the sample coded by one of the two research assistants.

Measures. The coders recorded three measures of the degree of buyer persistence. They used a scale ranging from 1,"not at all," to 5 , "extremely," to code qualitatively how "persistent" they perceived the buyer to be (ICC $=.93$ ). They also timed how many minutes the pair discussed the legal liability issue during the negotiation (ICC $=.91$ ). Finally, they counted how many times the buyer asked for a concession on the liability issue (i.e., asked the seller to accept some of the liability) (ICC $=.94)$. The time devoted to achieving an objective and the number of attempts one makes to achieve an objective are both common indicators of task persistence (e.g., Dweck \& Gilliard, 1975; Grant et al., 2007; Sandelands, Brockner, \& Glynn, 1988; Shah, 2003).

All three indicators of the degree of buyer persistence produced the same pattern of effect. For the 
sake of parsimony, we report their results as a composite indicator of buyer persistence. Because the variables were measured on different scales, we standardized them before combining them into a mean composite $(\alpha=.90)$.

The coders rated two sets of indicators of the manner of buyer persistence. Using a frequency scale ( 1 = "not at all," 5 = "very often"), the coders rated the buyers' use of the following direct influence strategies: persuasion (i.e., attempts to convince the seller to concede) (ICC $=.94)$, demands (i.e., insistent statements, such as "You have to do better than that") (ICC $=.76$ ), and positional commitments (i.e., refusals to move from one's position) (ICC $=.83$ ) (direct influence $\alpha=.76$ ). These direct influence tactics involve verbal forms of communication, which are consistent with classic descriptions of competitive bargaining behavior (Pruitt, 1981; Walton \& McKersie, 1965) and highstatus influence strategies (Falbo \& Peplau, 1980; Howard et al., 1986; Johnson, 1976).

Using the same five-point frequency scale, the coders also rated the buyers' use of the following indirect influence strategies: body language (e.g., slumped posture, arms crossed) (ICC $=.85)$, tone of voice (e.g., disappointment, sarcasm) (ICC $=.93$ ), and emotional displays of annoyance (ICC $=.93$ ) and frustration (ICC $=.93$ ) (indirect influence $\alpha=$ .93). In contrast to the direct verbal communication of what a persister wants from a naysayer, these indirect influence strategies involve nonverbal ways of communicating dissatisfaction; they implicitly as opposed to explicitly convey a desire for the naysayer to act differently. Sending these types of indirect nonverbal, emotional messages is characteristic of low-status influence strategies (Falbo \& Peplau, 1980; Howard et al., 1986; Johnson, 1976).

Finally, the coders rated the sellers' (naysayers') overall competitiveness during the negotiation. On separate scales ( $1=$ "not at all, $5=$ "extremely"), the coders evaluated how "competitively" (ICC = .72 ) and how "cooperatively" (ICC $=.77$ ) the sellers behaved overall in the negotiation $(\alpha=.96$, with "cooperatively" reverse coded). Competitive was defined as "trying to get the largest slice of the pie possible for themselves." Cooperative was defined as "trying to find win-win solutions to maximize the payoffs for both parties."

We measured the buyers' (the persisters') individual negotiation performance on the basis of the total dollars gained from the negotiation. When categorizing buyers as either high- or low-performing, we used a median split based on the dollars gained by the buyers from the negotiation. We measured joint gains as the total dollars gained by a buyer-seller pair in their negotiation.

\section{Results and Discussion}

Eight pairs failed to reach an acceptable agreement. We removed these impasse cases because it was evident that one or more of the parties had failed to follow instructions. Rather than attempt to draw inferences about whether the parties' misdirection was authentic or strategic, we focused our analysis on the comparable cases in which parties reached agreement, for two reasons. First, impasse cases could not be included in the performance analysis, which was a central component of the study. Second, they appeared to fall randomly across experimental conditions (4 male buyers with 3 male and 1 female seller; 4 female buyers with 3 female and 1 male seller). The final sample contained 57 pairs: 16 female buyer-female seller, 14 female buyer-male seller, 12 male buyer-female seller, and 15 male buyer-male seller.

Degree of buyer persistence. As predicted, we observed a significant interaction effect of persister gender by naysayer gender on buyer persistence $\left(F[1,53]=10.39, p<.01, \eta^{2}=0.16\right)$ and no significant main effects for persister gender or naysayer gender $(F s<2.75$, $p$ 's $>.10)$. Female buyers were significantly more persistent with male than with female naysayers $(t[28]=2.59, p=.02, d=$ 0.98 ; male naysayer mean $=0.58$, s.d. $=0.68$; female naysayer mean $=-0.17$, s.d. $=0.88$ ). Male buyers were marginally significantly more persistent with female than with male naysayers $(t[25]=2.00, p=$ $.06, d=.80$; male naysayer mean $=-0.51$, s.d. $=$ 0.77 ; female naysayers mean $=0.18$, s.d. $=1.01$ ). Female buyers were significantly more persistent with male naysayers than male buyers $(t[27]=$ $4.02, p<.001, d=1.55$ ), but not with female naysayers $(t[26]=0.98, p=.34, d=0.38)$.

Degree of buyer persistence, naysayer competitiveness controlled. We constrained the sellers (the naysayers) from making any concessions on the liability issue, but we could not control their overall competitiveness in the negotiation directed toward the buyers (the persisters). This left open the possibility that female buyers were more persistent toward male than female naysayers because male naysayers behaved more competitively toward them than did female naysayers. Therefore, to test Hypothesis 1, we conducted an analysis of covariance (ANCOVA) of the effects of persister gender and naysayer gender on buyer persistence, controlling for naysayer competitiveness.

After inserting a control for overall naysayer competitiveness, we again observed a significant interaction effect of persister gender by naysayer gender on buyer persistence $(F[1,52]=4.51, p<$ $.04, \eta^{2}=0.08$ ) and no significant main effects for 
persister gender or naysayer gender $\left(F_{\mathrm{S}}<1.95\right.$, $p$ 's $>$.16). Naysayer competitiveness had a significant effect on buyer persistence $(F[1,52]=11.12$, $\left.p<.01, \eta^{2}=0.18\right)$. The more competitively the sellers (the naysayers) behaved in the negotiation, the more persistent the buyers were on the liability issue $(r=.51)$.

As depicted in Figure 2, the pattern of results supported Hypothesis 1. Controlling for naysayer competitiveness, female buyers were significantly more persistent on the liability issue with male than with female naysayers $(F[1,27]=4.98, p=$ $.03, \eta^{2}=0.16$; male naysayer estimated marginal mean $=0.53$, s.e. $=0.21$; female naysayer estimated marginal mean $=-0.12$, s.e. $=0.20$ ). Naysayer gender had no significant effect on male buyers' persistence $\left(F[1,24]=0.36, p=.56, \eta^{2}=0.02\right.$; male naysayer estimated marginal mean $=-0.29$, s.e. $=0.21$; female naysayer estimated marginal mean $=-0.09$, s.e. $=0.23$ ).

Manner of buyer persistence. Because the measures of direct and indirect influence were rated in terms of their frequency of use, they were highly correlated with the degree of buyer persistence (di- rect influence $r=.82$; indirect influence $r=.71$ ). They were also correlated with one another $(r=$ .78). When persisting on the liability issue, female buyers were rated higher in indirect influence than male buyers (female mean $=2.22$, s.d. $=1.03$; male mean $=1.71,0.89 ; t[55]=2.00, p=.05, d=0.54$ ), but there was no gender difference in reliance on direct influence (female mean $=2.15$, s.d. $=0.90$; male mean $=1.86$, s.d. $=0.98 ; t[55]=1.17, p=.25$, $d=0.32$ ).

We analyzed the manner of buyer persistence by comparing the buyers' relative reliance on direct as opposed to indirect influence behaviors, because reliance on more direct than indirect influence would fit a characteristically high-status influence profile, and reliance on more indirect than direct influence would fit a characteristically low-status influence profile. We predicted in Hypothesis 2 that female persisters would use a more characteristically low-status influence style-more indirect than direct-when negotiating with male as compared to female naysayers.

To make this comparison, we used within-subjects analyses of variance. Direct and indirect influ-

FIGURE 2

Study 2: Estimated Marginal Mean Persistence by Persister Gender and Naysayer Gender, Naysayers' Overall Competitiveness during Negotiation Controlled ${ }^{a}$

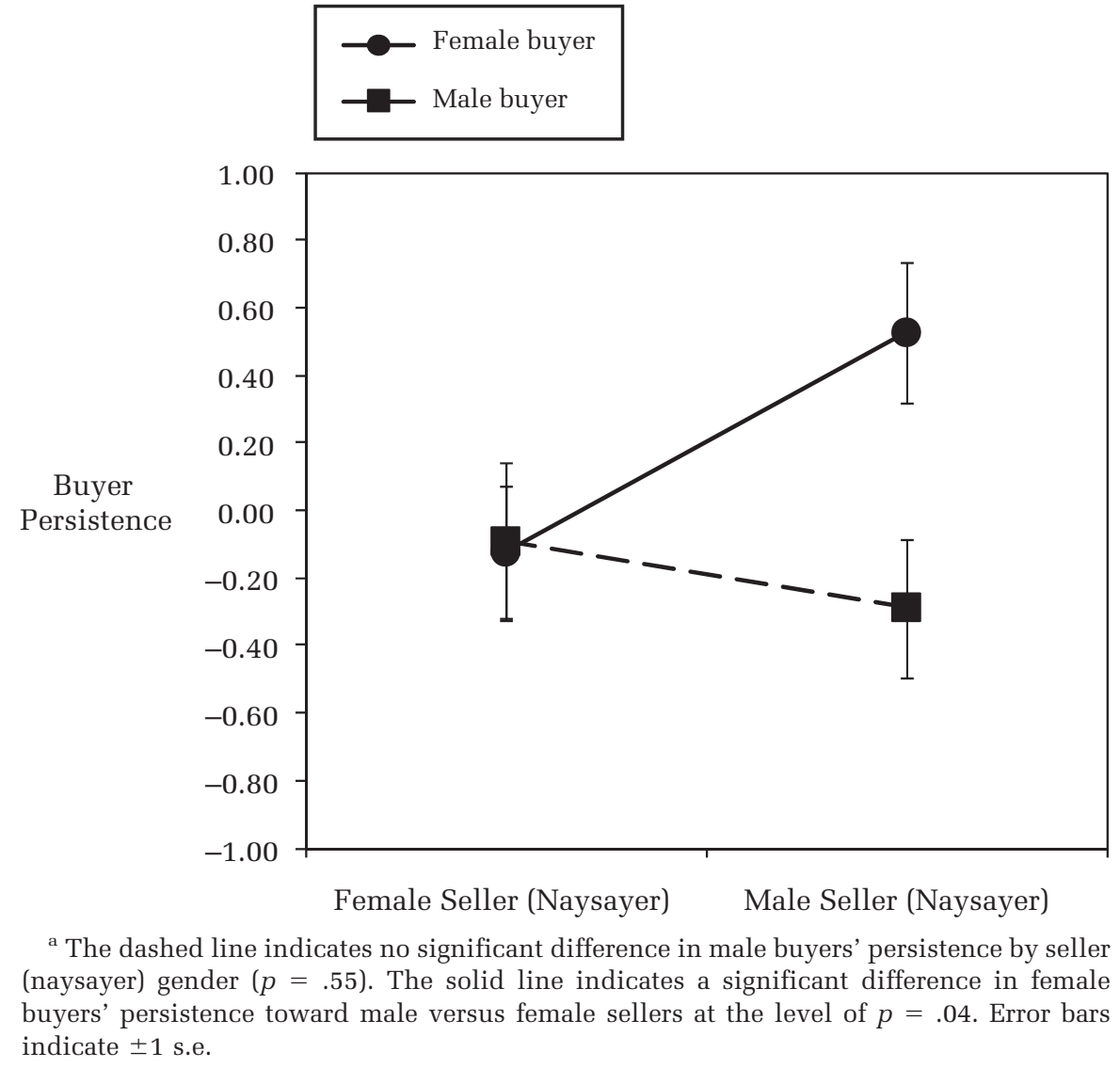


ence were our within-subjects dependent measures, and persister gender and naysayer gender were our between-subjects independent measures. In this way, we could test whether persister gender, naysayer gender, or their interaction influenced the buyers' relative reliance on direct as opposed to indirect influence measures.

As predicted, tests of within-subjects effects showed a significant persister gender by naysayer gender interaction $\left(F[1,53]=6.39, p=.02, \eta^{2}=\right.$ 0.11) on persisters' use of direct versus indirect influence. There were no main effects for persister or naysayer gender $(F s<2.18$, $p$ 's $>.14)$. For female buyers, there was a significant within-subjects effect of naysayer gender $(F[1,28]=7.22, p=.01$, $\eta^{2}=0.21$ ). As we hypothesized, when persisting on the liability issue, female buyers relied significantly more on indirect than direct influence with male naysayers $(t[13]=2.43, p=.03, d=1.35$, mean difference $=0.42$, s.e. $=0.17$ ) but not with female naysayers $(t[15]=1.37, p=.19, d=0.71$, mean difference $=-0.23$, s.e. $=0.67$ ). Naysayer gender had no effect on male buyers' use of direct versus indirect influence when persisting $(F[1,25]=$ $0.65, p=.43, \eta^{2}=0.03$ ).

Degree of persistence and performance. Buyers gained $\$ 11.55$ on average (above the show-up fee) from the negotiation. As predicted in Hypothesis 3, the degree of buyer persistence on the liability issue was positively correlated with the buyers' individual economic payoffs from the negotiation $(r=.46)$. There was no correlation $(r=-.08)$ between buyer persistence and joint gains (i.e., the total payoff for a dyad).

Table 1 summarizes results of an ANOVA of buyer performance by buyer (persister) gender and seller (naysayer) gender and of an ANCOVA controlling for buyer persistence. Table 2 presents estimated marginal means from the ANOVA and ANCOVA models. As shown in the ANOVA model, there was a significant main effect for buyer (per- sister) gender on performance $(F[1,53]=4.22, p<$ .05). Overall, male buyers earned $\$ 1.51$ more from the negotiation than did female buyers.

Comparing the effects of buyer (persister) gender in the ANOVA and ANCOVA models, one sees that controlling for buyer persistence increases the statistical significance of buyer gender on buyer performance $(F[1,52]=13.36, p=.001)$ and nearly triples its effect size (i.e., $\eta^{2}=0.07$ vs. $\eta^{2}=0.20$ ). In terms of estimated marginal mean performance (see Table 2), these models suggest that the male advantage in buyer performance would have been about 1.5 times greater if male and female buyers had used the same level of persistence (ANOVA model estimated mean difference $=-\$ 1.51$ vs. ANCOVA model estimated mean difference $=-\$ 2.24$ ).

The ANCOVA also revealed a significant interaction effect of buyer (persister) gender by seller (naysayer) gender on buyer performance $(F[1,52]=$ $4.01, p=.05)$. Controlling for buyer persistence, we found a significant effect for buyer gender on performance with male sellers $(F[1,26]=6.13, p=$ $.02, \eta^{2}=0.19$ ) but not on performance with female sellers $\left(F[1,25]=0.72, p=.40, \eta^{2}=0.03\right)$. As summarized in Table 2, comparison of estimated marginal means from the two models suggests that the gender gap in buyer performance with male sellers would have been 2.5 times greater if male and female buyers had used the same level of persistence (ANOVA model estimated mean difference $=-\$ 1.41$ vs. ANCOVA model estimated mean difference $=-\$ 3.55$ ). In sum, these findings indicate that female buyers' extra persistence with male sellers, which is depicted in Figure 2, helped reduce the gender gap in negotiation performance.

Manner of persistence and performance. In Hypothesis 4 , we predicted that the effect of naysayer gender on the manner of female buyers' persistence (i.e., more indirect than direct with male as compared to female naysayers) would be stronger with higher-performing female negotiators. To test this,

TABLE 1

Study 2: Analyses of Variance and Covariance of Buyer Performance, Demonstrating Effects of Controlling for Buyer Persistence

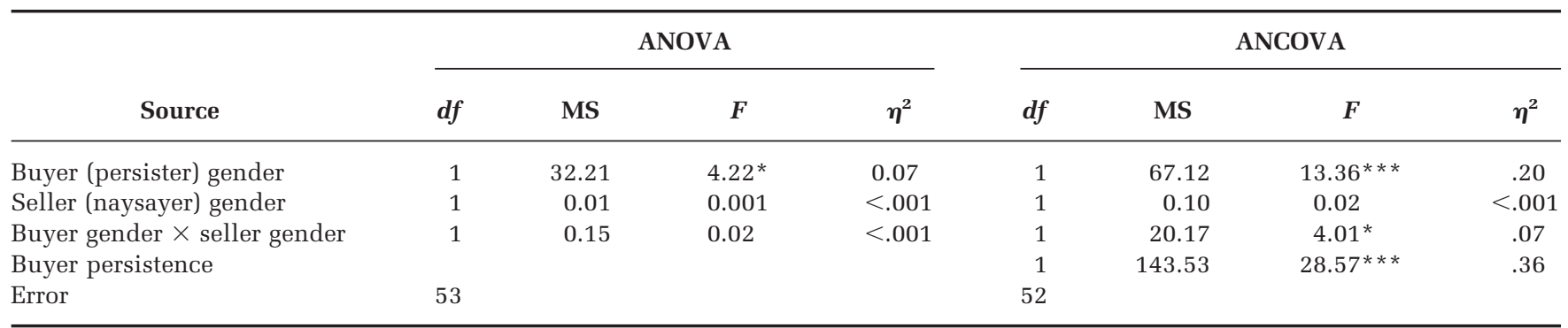

\footnotetext{
${ }^{*} p \leq .05$

$* * * p<.001$
} 
TABLE 2

Study 2: Estimated Marginal Means from ANOVA and ANCOVA Models of Buyer Performance

\begin{tabular}{|c|c|c|c|c|c|c|}
\hline \multirow[b]{3}{*}{ Buyer (Persister) } & \multicolumn{3}{|c|}{ ANOVA } & \multicolumn{3}{|c|}{ ANCOVA } \\
\hline & \multirow[b]{2}{*}{ Overall } & \multicolumn{2}{|c|}{ Seller (Naysayer) } & \multirow[b]{2}{*}{ Overall } & \multicolumn{2}{|c|}{ Seller (Naysayer) } \\
\hline & & Male & Female & & Male & Female \\
\hline \multicolumn{7}{|l|}{ Male } \\
\hline Mean & 12.36 & 12.29 & 12.42 & 12.68 & 13.29 & 12.06 \\
\hline$n$ & 27 & 15 & 12 & 27 & 15 & 12 \\
\hline \multicolumn{7}{|l|}{ Female } \\
\hline Mean & 10.84 & 10.89 & 10.80 & 10.44 & 9.74 & 11.13 \\
\hline s.e. & 0.51 & 0.74 & 0.69 & 0.42 & 0.64 & 0.56 \\
\hline$n$ & 30 & 14 & 16 & 30 & 14 & 16 \\
\hline
\end{tabular}

we used within-subjects analysis of variance with direct and indirect influence as our within-subjects dependent measures and high versus low (female) performance (based on a median split) and naysayer gender as our between-subjects independent measures.

The within-subjects analyses revealed a significant main effect for naysayer gender on women's use of direct versus indirect influence when per- sisting $\left(F[1,26]=8.11, p<.01, \eta^{2}=0.24\right)$. However, this effect was qualified by a significant interaction effect of high/low performer by naysayer gender $\left(F[1,26]=9.69, p<.01, \eta^{2}=0.27\right)$.

As depicted in Figure 3 , the pattern of means supported Hypothesis 4. For high-performing female buyers, mean differences in the use of direct versus indirect influence strategies when persisting on the liability issue differed significantly by nay-

FIGURE 3

Study 2: High- and Low-Performing Female Buyers' Use of Direct and Indirect Influence When Persisting, by Naysayer Gender ${ }^{\mathrm{a}}$

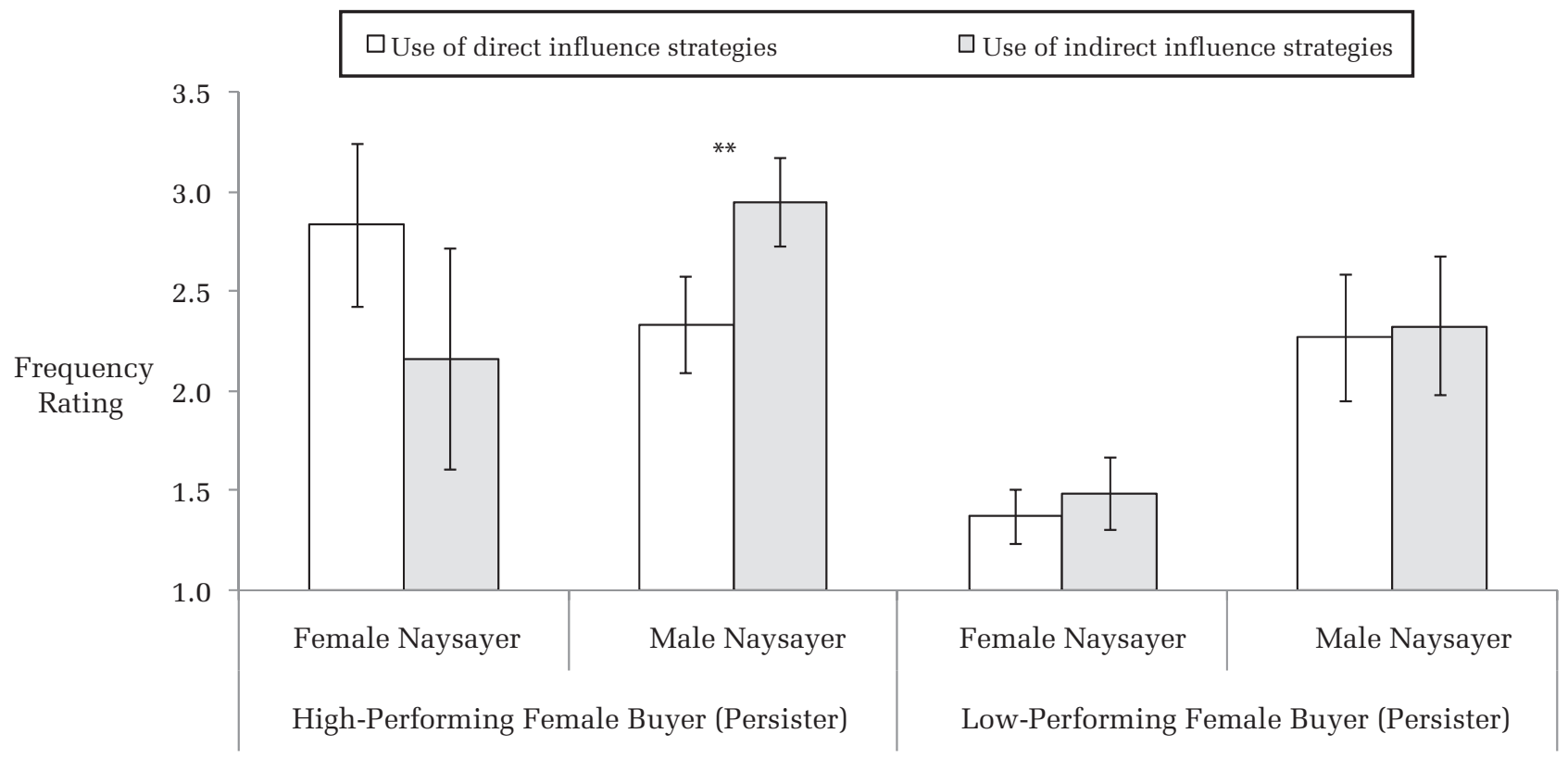

${ }^{a}$ Asterisks indicate significant difference at the level of $p=.01$ in the frequency of use of direct versus indirect influence strategies. Error bars indicate \pm 1 s.e. 
sayer gender (male naysayer mean difference $=$ -0.61 , s.d. $=0.56$; female naysayer mean difference $=0.67$, s.d. $=0.82 ; t[14]=3.72, p<.01, d=$ 1.99). For low-performing female buyers, mean differences in the use of direct vs. indirect influence did not vary by naysayer gender (male naysayer mean difference $=-0.06$, s.d. $=0.67$; female naysayer mean difference $=-0.12$, s.d. $=0.16 ; t[12]=$ $0.25, p=.80, d=0.14$ ).

These analyses do not allow us to say anything about causation-that is, whether women who adapt the manner of their persistence (influence style) to a naysayer's gender perform better in negotiation. However, this pattern of effect is consistent with research showing that it behooves women (even more than men) to calibrate their communication style to their target of influence (Carli, 1990; Flynn \& Ames, 2006).

In sum, the results of Study 2 replicate the interactive effects of persister gender and naysayer gender on the degree of negotiation persistence reported in Study 1. But, in Study 2, we show these effects using observation-based measures. In Study 2, we also found support for our hypotheses with regard to the manner of negotiation persistence and negotiation performance. Female negotiators persisted more strongly with male than with female naysayers, but they did so in a more stereotypically low-status (more indirect than direct) manner. With regard to negotiation performance, we found that this shift in women's persistence depending on naysayer gender appeared functional to the extent that heightened persistence with male naysayers helped women close the gender gap in negotiation payoffs, and adaptation of the manner of persistence to naysayer gender was associated with higher performance for female negotiators.

\section{GENERAL DISCUSSION}

Our findings contribute to the psychological literature on gender in negotiation in two important respects. First, these studies are the first to illuminate directly some of the ways in which gender influences persistence in negotiation. Our results challenge the sex-stereotypic intuition that men persist more than women, showing that it is the gender composition of a negotiating dyad that matters more than the gender of an individual negotiator, and that women persist as much as men and do so even more with male counterparts than with female ones. Moreover, by opening the proverbial black box of the negotiation process, we have gained insights that would not be apparent from the more common examination of participants' expectations and outcomes. We see that women adapt not only the degree of their persistence but also its manner, so that they persist more, but in more indirect ways, with male than with female naysayers. Linking process and performance measures, we see that the gender gap in negotiation performance, particularly with male counterparts, is not attributable to a failure on the part of women to stand their ground. By shining a light on the relationship between gender and persistence in negotiation, these findings also highlight the larger importance of examining more thoroughly the mechanisms of gender effects on negotiation performance, lest one settle too quickly on stereotypical inferences.

The second main contribution of this research is its demonstration of the importance of the gender composition of dyads for understanding gender effects in negotiation. Analyzing the meaning of gender in negotiation contexts, we theorized that effects are a product of expectations for self and other in interaction, which are more complex than the straightforward fulfillment of sex-stereotypic prophecies. Research on gender in social behavior suggests strongly that more is learned about gender in social interaction when researchers shift perspective from gender differences to the role of gender in context (Deaux \& Major, 1987). Further, we can make more refined predictions about gender at the dyadic than the individual level (Deaux \& LaFrance, 1998; Hall, 1984; Maccoby, 1998).

If we had constrained ourselves conceptually to individual-level gender effects or had analyzed only mixed-gender or same-gender dyads, we would likely have obtained null results. Researchers examining gender in negotiation should incorporate this dyadic perspective into their theorizing and methodological designs and explore other dimensions of negotiation (e.g., offer exchange) that might be better explained at the dyadic than at the individual level.

\section{Limitations and Future Directions}

Our results support our theoretical arguments, but they are also limited in some respects, particularly in the research approach. Although our methods offer significant advantages, certain methodological drawbacks are worth noting. For example, we operationalized persistence as continuing to negotiate in the face of "no." But, of course, persistence can be manifested in a wide array of behaviors, such as working around a naysayer or foregoing immediate benefits for the sake of greater future gains-negotiating strategies that might be advantageous to "creating" as well as "claiming" value (Lax \& Sebenius, 1986). Future research is needed to 
examine the extent to which our findings generalize to a broad range of persistence behaviors.

Our studies also do not examine whether more persistent negotiators are more prone to impasse. In Study 1, agreement between the parties was not possible, and in Study 2 we excluded the impasse cases from analysis. Future research should expand the study of persistence and performance to include failure to reach agreement as an outcome variable.

Future research could also test the generalizability of our findings across negotiation contexts. We recognize that situational factors other than those captured in our studies may trigger gender effects. For instance, researchers could explore how various factors, such as whether one is negotiating for oneself versus another (Bowles et al., 2005), the personal or organizational relationships between the parties (McGinn \& Keros, 2002), or the gender character of the negotiation situation (e.g., the subject of negotiation) influence the effects of gender on negotiation persistence. Although our laboratory controls enhance the internal validity of our findings, they constrain our potential to make broad generalizations about negotiations in organizations, which are, in practice, multiply determined by the relationships among direct and indirect parties and other behavioral cues in a given work context.

Another related consideration worthy of investigation is how other forms of ascribed status (e.g., race) or achieved status (e.g., organizational rank, expertise) might moderate these results. For instance, previous experimental research has shown that patterns of dominance and deference in mixedgender work groups shift from being correlated with gender to being correlated with other forms of social power (e.g., task expertise) when power is distributed explicitly across gender lines (Dovidio, Ellyson, Keating, \& Heltman, 1988; Wood \& Karten, 1986). This research could also be extended by manipulating status relations within negotiating dyads and testing those effects on persistence behavior.

Finally, we found that women's extra persistence with male counterparts reduced the gender gap in negotiation performance but did not eliminate it. This suggests that a failure to persist is an unlikely explanation for the gender gap in negotiation performance, but it still leaves unanswered why men tend to negotiate a larger slice of the pie than their female counterparts.

\section{Implications for Theory and Practice}

Finally, this work has implications for the study of gender in organizations more broadly. Negotiation is a fundamental form of coordination and conflict management in organizations. However, our findings are also relevant to the dynamics of resistance and persistence in everyday interpersonal influence situations that would not typically be recognized as "negotiations."

This research has further implications for how we talk outside of academia about the effects of sex stereotypes on organizational influence because it illustrates how women are not simply trapped by a choice between fulfilling the masculine or feminine stereotype. Women can and do assert themselves effectively when encountering resistance, but they do not necessarily do so in stereotypically masculine ways. The communication-through classrooms, training programs, or the press- of oversimplified sex-stereotypic effects on negotiation or other influence processes risks reifying the phenomena we are studying, by persuading managers that women are caged in behavioral traps in ways they are not.

\section{Conclusion}

The present research demonstrates effects of gender on negotiation persistence that are counterintuitive and fundamentally important to understanding gender effects on negotiation performance. We offer a novel perspective on the implications of gender stereotypes in negotiation by analyzing their implications for behavior at the dyadic level. We find that, rather than simply acquiescing more than men, women adapt their behavior to the gender of their negotiating counterparts-becoming more persistent with male naysayers than with female ones, but doing so using a more characteristically low-status influence style with the male naysayers than with the female naysayers. Taken together, our findings suggest that gender effects in negotiation may be best understood at the dyadic as opposed to the individual level and should be explored in terms of negotiation processes as well as outcomes.

\section{REFERENCES}

Babcock, L., \& Laschever, S. 2003. Women don't ask. Princeton, NJ: Princeton University Press.

Bandura, A. 1982. Self-efficacy mechanism in human agency. American Psychologist, 37: 122-147.

Barley, S. R. 1991. Contextualizing conflict: Notes on the anthropology of disputes and negotiations. In M. H. Bazerman, B. H. Sheppard, \& R. Lewicki (Eds.), Research on negotiation in organizations, vol. 3: 165199. Greenwich, CT: JAI Press.

Bem, S. L. 1981. Bem sex-role inventory. San Francisco: Consulting Psychology Press.

Ben-Yoav, O., \& Pruitt, D. G. 1984. Resistance to yielding and the expectation of cooperative future interaction 
in negotiation. Journal of Experimental Social Psychology, 20: 323-335.

Bielby, W. T., \& Baron, J. N. 1986. Men and women at work: Sex segregation and statistical discrimination. American Journal of Sociology, 91: 759-799.

Blount, S. 1997. Buying a house. Evanston, IL: Dispute Resolution Research Center, Kellogg School of Management, Northwestern University.

Bontempo, R. 1994. Rio Copa negotiation exercise. New York: Columbia University.

Bowles, H. R., Babcock, L., \& Lai, L. 2007. Social incentives for gender differences in the propensity to initiate negotiations: Sometimes it does hurt to ask. Organizational Behavior and Human Decision Processes, 103: 84-103.

Bowles, H. R., Babcock, L., \& McGinn, K. L. 2005. Constraints and triggers: Situational mechanics of gender in negotiation. Journal of Personality and Social Psychology, 89: 951-965.

Bowles, H. R., \& McGinn, K. L. 2008. Untapped potential in the study of negotiation and gender inequality in organizations. In J. P. Walsh \& A. Brief (Eds.), Academy of Management annals, vol. 2: 99-132. New York: Routledge.

Brown, P., \& Levinson, S. C. 1987. Politeness: Some universals in language use. Cambridge, U.K.: Cambridge University Press.

Burgoon, M., Dillard, J. P., \& Ooran, N. E. 1983. Friendly or unfriendly persuasion: The effects of violations of expectations by males and females. Human Communication Research, 10: 283-294.

Calhoun, P. S., \& Smith, W. P. 1999. Integrative bargaining: Does gender make a difference? International Journal of Conflict Management, 10: 203-224.

Carli, L. L. 1990. Gender, language, and influence. Journal of Personality and Social Psychology, 59: 941951.

Carli, L. L., LaFleur, S. J., \& Loeber, C. C. 1995. Nonverbal behavior, gender, and influence. Journal of Personality and Social Psychology, 68: 1030-1041.

Catalyst. 2007. The double-bind dilemma for women in leadership: Damned if you do, doomed if you don't. New York: Catalyst.

Charles, M., \& Bradley, K. 2009. Indulging our gendered selves? Sex segregation by field of study in 44 countries. American Journal of Sociology, 114: 924-976.

Cherry Wilkinson, L., Lindow, J., \& Chiang, C.-P. 1985. Sex differences and sex segregation in students' small-group communication. In L. C. Wilkinson \& C. B. Marrett (Eds.), Gender influences in classroom interaction: 185-207. Orlando, FL: Academic Press.

Conway, M., Pizzamiglio, M. T., \& Mount, L. 1996. Status, communality, and agency: Implications for stereotypes of gender and other groups. Journal of Personality and Social Psychology, 71: 25-38.
Cowan, G., Drinkard, J., \& MacGavin, L. 1984. The effects of target, age, and gender on use of power strategies. Journal of Personality and Social Psychology, 47: 1391-1398.

Deaux, K., \& Kite, M. E. 1987. Thinking about gender. In B. B. Hess \& M. M. Ferree (Eds.), Analyzing gender: A handbook of social science research: 92-117. Thousand Oaks, CA: Sage.

Deaux, K., \& LaFrance, M. 1998. Gender. In D. T. Gilbert, S. Fiske, \& G. Lindsey (Eds.), The handbook of social psychology (4th ed.): 788-827. Boston: McGraw-Hill.

Deaux, K., \& Major, B. 1987. Putting gender into context: An interactive model of gender-related behavior. Psychological Review, 94: 369-389.

De Dreu, C. K. W., \& Gelfand, M. J. (Eds.). 2007. The psychology of conflict and conflict management in organizations. San Francisco: Jossey Bass.

De Dreu, C. K. W., Weingart, L. R., \& Kwon, S. 2000. Influence of social motives on integrative negotiation: A meta-analytic review and test of two theories. Journal of Personality and Social Psychology, 78: 889-905.

Diekman, A. B., \& Eagly, A. H. 2000. Stereotypes as dynamic constructs: Women and men of the past, present, and future. Personality and Social Psychology Bulletin, 26: 1171.

Diekmann, K. A., Tenbrunsel, A. E., \& Galinsky, A. D. 2003. From self-prediction to self-defeat: Behavioral forecasting, self-fulfilling prophecies, and the effect of competitive expectations. Journal of Personality and Social Psychology, 85: 672-683.

Dovidio, J. F., Ellyson, S. L., Keating, C. F., \& Heltman, K. 1988. The relationship of social power to visual displays of dominance between men and women. Journal of Personality and Social Psychology, 54: 233-242.

Dweck, C. S., \& Gilliard, D. 1975. Expectancy statements as determinants of reactions to failure: Sex differences in persistence and expectancy change. Journal of Personality and Social Psychology, 32: 1077-1084.

Eagly, A. H. 1987. Sex differences in social behavior: A social-role interpretation. Hillsdale, NJ: Erlbaum.

Eagly, A. H., \& Carli, L. L. 2007. Through the labyrinth. Boston: Harvard Business School Press.

Eagly, A. H., \& Steffen, V. J. 1984. Gender stereotypes stem from the distribution of women and men into social roles. Journal of Personality and Social Psychology, 46: 735-754.

Ely, R. J. 1995. The power of demography: Women's social constructions of gender identity at work. Academy of Management Journal, 38: 589-635.

Ely, R. J., \& Meyerson, D. E. 2000. Theories of gender in organizations: A new approach to organizational analysis and change. In B. M. Staw \& R. I. Sutton (Eds.), Research in organizational behavior, vol. 22: 103-151. New York: Elsevier. 
Falbo, T., \& Peplau, L. A. 1980. Power strategies in intimate relationships. Journal of Personality and Social Psychology, 38: 618-628.

Flynn, F. J., \& Ames, D. R. 2006. What's good for the goose may not be as good for the gander: The benefits of self-monitoring for men and women in task groups and dyadic conflicts. Journal of Applied Psychology, 91: 272-281.

Glick, P., Fiske, S. T., Mladinic, A., Saiz, J. L., Abrams, D., Masser, B., Adetoun, B., Osagie, J. E., Akande, A., Alao, A., Annetje, B., Willemsen, T. M., Chipeta, K., Dardenne, B., Dijksterhuis, A., Wigboldus, D., Eckes, T., Six-Materna, I., Exposito, F., Moya, M., Foddy, M., Kim, H.-J., Lameiras, M., Sotelo, M. J., Mucchi-Faina, A., Romani, M., Sakalli, N., Udegbe, B., Yamamoto, M., Ui, M., Ferreira, M. C., \& Lopez, W. L. 2000. Beyond prejudice as simple antipathy: Hostile and benevolent sexism across cultures. Journal of Personality and Social Psychology, 79: 763-775.

Goldin, C. 1990. Understanding the gender gap: An economic history of American women. New York: Oxford University Press.

Goodwin, M. H., \& Goodwin, C. 1987. Children's arguing. In S. U. Phillips, S. Steele, \& C. Tanz (Eds.), Language, gender and sex in comparative perspective: 200248. Cambridge, U.K.: Cambridge University Press.

Grant, A. M., Campbell, E. M., Chen, G., Cottone, K., Lapedis, D., \& Lee, K. 2007. Impact and the art of motivation maintenance: The effects of contact with beneficiaries on persistence behavior. Organizational Behavior and Human Decision Processes, 103: 53-67.

Grant, M. J., \& Sermat, V. 1969. Status and sex of other as determinants of behavior in a mixed-motive game. Journal of Personality and Social Psychology, 12: 151-157.

Hall, J. A. 1984. Nonverbal sex differences: Communication accuracy and expressive style. Baltimore: Johns Hopkins University Press.

Heilman, M. E. 1983. Sex bias in work settings: The lack of fit model. In B. M. Staw \& L. L. Cummings (Eds.), Research in organizational behavior, vol. 5: 269298. Greenwich, CT: JAI Press.

Heilman, M. E., \& Okimoto, T. G. 2007. Why are women penalized for success at male tasks? The implied communality deficit. Journal of Applied Psychology, 92: 81-92.

Howard, J. A., Blumstein, P., \& Schwartz, P. 1986. Sex, power, and influence tactics in intimate relationships. Journal of Personality and Social Psychology, 51: 102-109.

Jackman, M. R. 1994. The velvet glove: Paternalism and conflict in gender, class, and race relations. Berkeley: University of California Press.

Johnson, P. 1976. Women and power: Toward a theory of effectiveness. Journal of Social Issues, 32: 99-110.

Kelley, H. H., \& Stahelski, A. J. 1970. Social interaction basis of cooperators' and competitors' beliefs about others. Journal of Personality and Social Psychology, 16: 66-91.

Keltner, D., Young, R. C., Heerey, E. A., Oemig, C., \& Monarch, N. D. 1998. Teasing in hierarchical and intimate relations. Journal of Personality and Social Psychology, 75: 1231-1247.

Kimmel, M. J., Pruitt, D. G., Magenau, J. M., Konar-Goldband, E., \& Carnevale, P. J. 1980. Effects of trust, aspiration, and gender on negotiation tactics. Journal of Personality and Social Psychology, 38: 9-22.

King, J., Wesley, C., Miles, E. W., \& Kniska, E. W. 1991. Boys will be boys (and girls will be girls): The attribution of gender role stereotypes in a gaming situation. Sex Roles, 25: 607-623.

Kray, L. J., \& Thompson, L. 2005. Gender stereotypes and negotiation performance: A review of theory and research. In B. M. Staw \& R. Kramer (Eds.), Research in organizational behavior, vol. 26: 103-182. Greenwich, CT: JAI Press.

Kray, L. J., Thompson, L., \& Galinsky, A. 2001. Battle of the sexes: Gender stereotype confirmation and reactance in negotiations. Journal of Personality and Social Psychology, 80: 942-958.

Lax, D. A., \& Sebenius, J. K. 1986. The manager as negotiator: Bargaining for cooperation and competitive gain. New York: Free Press.

Leaper, C. 1991. Influence and involvement in children's discourse: Age, gender, and partner effects. Child Development, 62: 797-811.

Leaper, C., \& Holliday, H. 1995. Gossip in same-gender and cross-gender friends' conversations. Personal Relationships, 2: 237-246.

Locke, E. A., \& Latham, G. P. 2002. Building a practically useful theory of goal setting and task motivation: A 35-year odyssey. American Psychologist, 57: 705-717.

Maccoby, E. E. 1998. The two sexes: Growing up apart, coming together. Cambridge, MA: Belknap Press.

Matheson, K. 1991. Social cues in computer-mediated negotiations: Gender makes a difference. Computers in Human Behavior, 7: 137-145.

McCloskey, L. A., \& Coleman, L. M. 1992. Difference without dominance: Children's talk in mixed- and same-sex dyads. Sex Roles, 27: 241-257.

McFarlin, D. B., Baumeister, R. F., \& Blascovich, J. 1984. On knowing when to quit: Task failure, self-esteem, advice, and nonproductive persistence. Journal of Personality, 52: 138-155.

McGinn, K., \& Keros, A. 2002. Improvisation and the logic of exchange in socially embedded transactions. Administrative Science Quarterly, 47: 442-473.

Meeker, B. F., \& Weitzel-O’Neill, P. A. 1977. Sex roles and interpersonal behavior in task-oriented groups. American Sociological Review, 42: 91-105.

Miller, P. M., Danaher, D. L., \& Forbes, D. 1986. Sex- 
related strategies for coping with interpersonal conflict in children aged five and seven. Developmental Psychology, 22: 543-548.

Moskowitz, D. S., Suh, E. J., \& Desaulniers, J. 1994. Situational influences on gender differences in agency and communion. Journal of Personality and Social Psychology, 66: 753-761.

Orbell, J., Dawes, R., \& Schwartz-Shea, P. 1994. Trust, social categories, and individuals: The case of gender. Motivation and Emotion, 18: 109-128.

Pfeffer, J. 1981. Power in organizations. Boston: Pitman.

Piliavin, J. A., \& Martin, R. R. 1978. The effects of the sex composition of groups on style of social interaction. Sex Roles, 4: 281-296.

Pruitt, D. G. 1981. Negotiation behavior. New York: Academic Press.

Pruitt, D. G. 1998. Social conflict. In D. T. Gilbert, S. Fiske, \& G. Lindsey (Eds.), Handbook of social psychology (4th ed.): 470-503. Boston: McGraw-Hill.

Ridgeway, C. L. 1982. Status in groups: The importance of motivation. American Sociological Review, 47: 7688.

Ridgeway, C. L. 1997. Interaction and the conservation of gender inequality: Considering employment. American Sociological Review, 62: 218-235.

Ridgeway, C. L. 2006. Gender as an organizing force in social relations: Implications for the future of inequality. In F. D. Blau, M. B. Brinton, \& D. G. Grusky (Eds.), The declining significance of gender? 265287. New York: Russell Sage.

Ridgeway, C. L., \& Bourg, C. 2004. Gender as status: An expectation states theory approach. In A. H. Eagly, A. E. Beall, \& R. J. Sternberg (Eds.), The psychology of gender: 217-241. New York: Guliford Press.

Rosenthal, R. 1994. Interpersonal expectancy effects: A 30-year perspective. Current Directions in Psychological Science, 3: 176-179.

Rubin, J. Z., \& Brown, B. R. 1975. The social psychology of bargaining and negotiation. New York: Academic Press.

Rudman, L. A., \& Glick, P. 2001. Prescriptive gender stereotypes and backlash toward agentic women. Journal of Social Issues, 57: 743-762.

Sandelands, L. E., Brockner, J., \& Glynn, M. A. 1988. If at first you don't succeed, try, try again: Effects of persistence-performance contingencies, ego involvement, and self-esteem on task persistence. Journal of Applied Psychology, 73: 208-216.

Seligman, M. E., \& Schulman, P. 1986. Explanatory style as a predictor of productivity and quitting among life insurance sales agents. Journal of Personality and Social Psychology, 50: 832-838.

Sgan, M. L., \& Pickert, S. M. 1980. Cross-sex and samesex assertive bids in a cooperative group task. Child Development, 51: 928-931.
Shah, J. 2003. The motivational looking glass: How significant others implicitly affect goal appraisals. Journal of Personality and Social Psychology, 85: 424-439.

Sheldon, A. 1990. Pickle fights: Gendered talk in preschool disputes. Discourse Processes, 13: 5-31.

Sheldon, A. 1992. Conflict talk: Sociolinguistic challenges to self-assertion and how young girls meet them. Merrill-Palmer Quarterly, 38: 95-117.

Siegel, S., \& Fouraker, L. E. 1960. Bargaining and group decision making: Experiments in bilateral monopoly. New York: McGraw-Hill.

Snyder, M., \& Swann, W. B., Jr. 1978. Behavioral confirmation in social interaction: From social perception to social reality. Journal of Experimental Social Psychology, 14: 148-162.

Spence, J. T., \& Helmreich, R. L. 1978. Masculinity and femininity: Their psychological dimensions, correlates, and antecedents. Austin: University of Texas Press.

Strough, J., \& Berg, C. A. 2000. Goals as a mediator of gender differences in high-affiliation dyadic conversations. Developmental Psychology, 36: 117-125.

Stuhlmacher, A. F., Citera, M., \& Willis, T. 2007. Gender differences in virtual negotiation: Theory and research. Sex Roles 57: 329-339.

Stuhlmacher, A. F., \& Walters, A. E. 1999. Gender differences in negotiation outcome: A meta-analysis. Personnel Psychology, 52: 653-677.

Ury, W. 1993. Getting past no: Negotiating your way from confrontation to cooperation. New York: Bantam Books.

Walters, A. E., Stuhlmacher, A. F., \& Meyer, L. L. 1998. Gender and negotiator competitiveness: A metaanalysis. Organizational Behavior and Human Decision Processes, 76: 1-29.

Walton, R. E., \& McKersie, R. 1965. A behavioral theory of labor negotiations. New York: McGraw-Hill.

West, C., \& Zimmerman, D. H. 1987. Doing gender. Gender $\&$ Society, 1: 125-151.

Wharton, C. S. 2002. Framing a domain for work and family: A study of women in residential real-estate. Lanham, MD: Lexington Books.

Wood, W. 1987. Meta-analytic review of sex differences in group performance. Psychological Bulletin, 102: 5371.

Wood, W., \& Karten, S. J. 1986. Sex differences in interaction style as a product of perceived sex differences in competence. Journal of Personality and Social Psychology, 50: 341-347.

Word, C. O., Zanna, M. P., \& Cooper, J. 1974. The nonverbal mediation of self-fulfilling prophecies in interracial interaction. Journal of Experimental Social Psychology, 10: 109-120. 


\section{APPENDIX}

TABLE A1

Study 2: Point-Based Scoring System ${ }^{\text {a }}$

\begin{tabular}{|c|c|c|c|}
\hline \multicolumn{2}{|c|}{ Issues and Options } & Buyer Points & Seller Points \\
\hline \multicolumn{4}{|c|}{ Payment terms } \\
\hline A. & $\$ 20$ million & 300 & 0 \\
\hline B. & $\$ 21$ million & 270 & 25 \\
\hline C. & $\$ 22$ million & 240 & 50 \\
\hline D. & $\$ 23$ million & 210 & 75 \\
\hline E. & $\$ 24$ million & 180 & 100 \\
\hline F. & $\$ 25$ million & 150 & 125 \\
\hline G. & $\$ 26$ million & 120 & 150 \\
\hline H. & $\$ 27$ million & 90 & 175 \\
\hline I. & $\$ 28$ million & 60 & 200 \\
\hline $\mathrm{J}$. & $\$ 29$ million & 30 & 225 \\
\hline K. & $\$ 30$ million & 0 & 250 \\
\hline \multicolumn{4}{|c|}{ Noncompete period } \\
\hline A. & 10 years & 200 & 0 \\
\hline B. & 9 years & 180 & 20 \\
\hline C. & 8 years & 160 & 60 \\
\hline D. & 7 years & 140 & 100 \\
\hline E. & 6 years & 120 & 140 \\
\hline F. & 5 years & 100 & 180 \\
\hline G. & 4 years & 80 & 220 \\
\hline H. & 3 years & 60 & 260 \\
\hline I. & 2 years & 40 & 300 \\
\hline J. & 1 year & 20 & 340 \\
\hline K. & 0 years & 0 & 380 \\
\hline \multicolumn{4}{|c|}{$\begin{array}{l}\text { Number of family } \\
\text { employees retained }\end{array}$} \\
\hline A. & 0 & 300 & 0 \\
\hline B. & 1 & 270 & 60 \\
\hline C. & 2 & 240 & 120 \\
\hline D. & 3 & 210 & 200 \\
\hline E. & 4 & 180 & 260 \\
\hline F. & 5 & 150 & 320 \\
\hline G. & 6 & 120 & 380 \\
\hline H. & 7 & 90 & 440 \\
\hline I. & 8 & 60 & 500 \\
\hline J. & 9 & 30 & 560 \\
\hline K. & 10 & 0 & 620 \\
\hline \multicolumn{4}{|c|}{ Liability seller accepts } \\
\hline A. & $0 \%$ & 0 & 125 \\
\hline B. & $10 \%$ & 50 & Unacceptable \\
\hline C. & $20 \%$ & 110 & Unacceptable \\
\hline D. & $30 \%$ & 180 & Unacceptable \\
\hline E. & $40 \%$ & 260 & Unacceptable \\
\hline F. & $50 \%$ & 350 & Unacceptable \\
\hline G. & $60 \%$ & 440 & Unacceptable \\
\hline H. & $70 \%$ & 530 & Unacceptable \\
\hline I. & $80 \%$ & 620 & Unacceptable \\
\hline $\mathrm{J}$. & $90 \%$ & 710 & Unacceptable \\
\hline K. & $100 \%$ & 800 & Unacceptable \\
\hline
\end{tabular}

${ }^{\text {a }}$ Buyers were the persisters in all negotiations, and sellers were the naysayers. Parties had to reach agreement on one option for each issue and received one dollar for every 50 points they negotiated.
Hannah Riley Bowles (hannah_bowles@harvard.edu) is an associate professor at the John F. Kennedy School of Government at Harvard University. Her research focuses on micromechanisms of gender inequality in organizations, with particular emphasis on negotiation processes and how situational factors influence the effects of gender on negotiation behavior and outcomes. She received her doctorate from the Harvard Business School.

Francis Flynn (flynn_francis@GSB.stanford.edu) is a professor of organizational behavior at Stanford University. His research investigates how employees develop healthy patterns of cooperation, how stereotyping in the workplace is mitigated, and how leaders in organizations acquire power and influence. He received his doctorate from the University of California, Berkeley. 
Copyright of Academy of Management Journal is the property of Academy of Management and its content may not be copied or emailed to multiple sites or posted to a listserv without the copyright holder's express written permission. However, users may print, download, or email articles for individual use. 